\title{
IMPLICATIONS OF COVID-19 PANDEMIC ON HOUSEHOLD FOOD SECURITY: EXPERIENCE FROM SARAWAK, MALAYSIA
}

\author{
Regina Garai Abdullah* \\ Universiti Malaysia Sarawak \\ Neilson Ilan Mersat \\ Universiti Malaysia Sarawak \\ Swee-Kiong Wong \\ Universiti Malaysia Sarawak
}

\begin{abstract}
This paper discusses how household food security is affected by the Covid-19 pandemic, using examples from Sarawak, Malaysia. Food security in Sarawak was affected by the implementation of the Movement Control Order (MCO) that was introduced to curb the spread of the Covid-19 disease. The MCO, and the subsequent phases that followed, imposed a varying degree of restrictions on movements in the country. This measure had serious repercussions on food security as it affects the distribution of food as well as how people access food. This raises questions of how secure households are in terms of food security, how do they ensure food security for their households and what are their greatest challenge in ensuring food security. This paper seeks to address those questions by examining the experiences and perceptions on food security during the pandemic based on the responses of 235 respondents. Findings indicated that most households are food secure i.e. having similar access to food as prior to MCO and have not skipped any meals. In order to achieve this, households had to resort to various measures including switching their food sources, shopping online, and going without their preferred food. Significantly, the finding shows that food security means more than just having enough food but should also incorporate elements of variety, types and quantity of food. It also shows that the greatest challenge in achieving and maintaining household food security lies in the way household cope with the changes brought, both directly and indirectly, by the pandemic.
\end{abstract}

Keywords: Covid-19 Pandemic, Food Security, Food Accessibility, Food Availability, Sarawak.

Received:1 August 2020

Accepted: 31 December 2020

https://doi.org/10.33736/ijbs.3159.2021

\section{INTRODUCTION}

The World Health Organisation (WHO) declared the Coronavirus disease (Covid-19) as a pandemic on 11 March 2020 (WHO, 2020). Many countries then declared generalised lockdowns and quarantines as a measure to combat the spread of the disease. A week after the WHO's

\footnotetext{
- Corresponding author: Faculty of Social Sciences and Humanities, Universiti Malaysia Sarawak, 94300 Kota Samarahan, Sarawak, Malaysia; Tel: +60 (0)82 584107; Email: argarai@unimas.my
} 
announcement, the Malaysian Government implemented the Movement Control Order (MCO) as a measure to curb the spread of Covid-19 in the country. The MCO, which started on 18 March 2020, was extended into another five phases, with varying degrees of restriction. At the time of writing, Malaysia is on its fifth phase, known as the Recovery Movement Control Order (RMCO) period, which is due to end on 31 August 2020. During the MCO, and its subsequent phases, restrictions were put on the movement of people, goods and transport, and leading to what Bhavani \& Gopinath (2020) describe as the breakdown of food supply chains, and loss of perishable produce. Similarly, the Food and Agriculture Organisation (FAO) highlights how the pandemic could cause great disruption on marketing, logistics and trading systems that could make food occasionally unavailable in some locations (FAO, 2020).

Even before the start of the Covid-19 pandemic, food security has always been recognised as one of the pertinent global concerns (Ansah, Gardebroek \& Ihle, 2019; Galanakis, 2020; Loopstra, 2020; Maxwell, 1996; Rosegrant \& Cline, 2003). Food security is a complex sustainable development issue, linked to health through malnutrition, but also economic development, environment and trade (Capone, El Bilali, Debs, Cardone \& Driouech, 2014: 13). Food security has been included as one of the goals in the Millennium Development Goals (MDGs) in 2000 and, subsequently, in the 2030 Sustainable Development Goals (SDGs) as well. The target for the MDGs is to halve the proportion of people who suffer from hunger between 1990 and 2015. Its complexity makes the target difficult to achieve (Ansah et al., 2019). After the end of the MDGs period, the issue of food security continues to become one of the central targets of the SDGs as well. Galanakis (2020), for instance, highlights how the food systems play a crucial role in achieving the SDGs. Specifically, SDG 2 which aims to end hunger through achieving food security and improved nutrition, and SDG 12 which seeks to ensure sustainable consumption and production.

During this period of restricted movement due to Covid-19 pandemic, global food security becomes more critical. Bublitz, Czarkowski, Hansen, Peracchio \& Tussler (2020) argue that the Covid-19 pandemic has exposed systemic vulnerabilities in food access for people experiencing hunger. The FAO (2020), for example, warns that the economic turmoil caused by the Covid-19 pandemic threatens both economic and physical access to food. Images of people queuing up at supermarkets, and empty shelves hinted at how people are trying to secure their essential supply, including food items, during the pandemic. In many countries, panic buying, food hoarding and stockpiling became a serious pandemic-related issue. Such images provoke us to think about inequality, poverty and vulnerable populations and their challenges in accessing sufficient food for their households. Most significantly, the pandemic raises concern about food security as a result of these three crucial development issues (Bhavani \& Gopinath, 2020; Bublitz et al., 2020; FAO, 2020; Galanakis, 2020; Loopstra, 2020).

This concern raises questions of how secure are households in terms of food security, how do they cope in ensuring that their households are food secure during this particular period of restricted movement and what are their greatest challenge in achieving and/or maintaining their household food security. Thus, this paper seeks to address those three questions by examining people's experiences and perceptions on food security during the Covid-19 pandemic, using data collected in Sarawak, Malaysia. 


\section{LITERATURE REVIEW}

Food security exists when all people, at all times, have physical and economic access to sufficient, safe and nutritious food that meets their dietary needs and food preferences for an active and healthy life (FAO, 1996). This definition focuses on the multi-dimensional issue of food security: availability, access, utilisation and stability. These are the four pillars of food security (FAO, 2006). Earlier definitions of food security, especially in the 1970s and 1980s, tend to focus more on the issues of food supply and availability, and food accessibility respectively. In the 1970s, for example, food security is defined as the availability at all times of adequate world food supplies of basic foodstuffs to sustain a steady expansion of food consumption (FAO, 2006). In this case, food availability is defined as the physical availability of food in an area, which according to Mutiah \& Istiqomah (2017), can be obtained either from the domestic production, imports or food aid.

Figure 1: The four pillars of food security

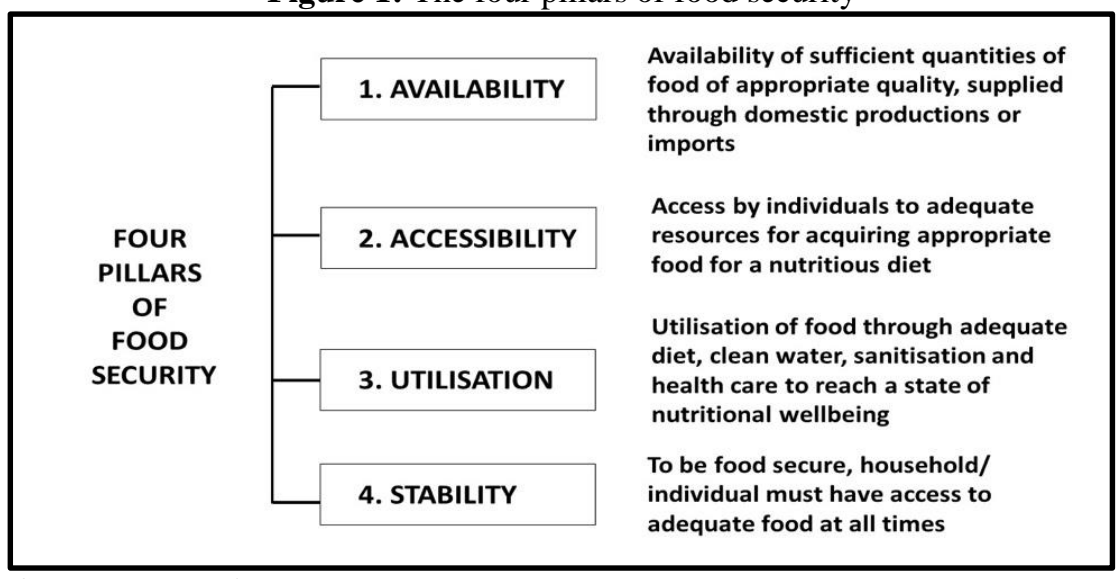

Source: FAO (2006)

This notion of food security was expanded to include the concept of access in the 1980s. FAO (1983) defines food security as ensuring that all people at all times have both physical and economic access to the basic food that they need. This definition stresses on the significance and ability of individuals and households to obtain sufficient food to meet their needs, regardless of its sources (Mutiah \& Istiqomah, 2017). Then in the 1990s, the definition of food security was further expanded to acknowledge its multi-dimensional nature. This is when food security's definition encompasses the elements of food availability, food accessibility, utilisation and stability of food as introduced by the World Food Summit in 1996 (FAO, 1996). These four pillars of food security are summarised in Figure 1 above.

Food security is a significant regional and global issue and that ensuring food security is everyone's responsibility (Mat Akhir, Omar \& Abd Hamid, 2009). They further elaborated that food security should be addressed at different levels of organisation, from individual to household, community, regional, national and global levels. For example, at the national and regional levels, the government is responsible to ensure that the nation is food secure while, at household level, every member of the household is responsible to secure enough food for every household member (Mat 
Akhir et al., 2009). The former emphasises the crucial roles of food-related sectors such as food producers, distributors, and processors as well as appropriate food-related policies.

Past studies that focus on household food security found that food security at household level has always been associated with low socio-economic status, inadequate dietary intake and poor nutritional status (Bhavani \& Gopinath, 2020; Cooper, 2013; Sharif \& Ang, 2001). It has been argued that examining food availability on its own may not be enough as there might be cases of where the food is widely available but people have problem accessing those food (Ansah et al., 2019; Maxwell \& Smith, 1992; Mutiah \& Istiqomah, 2017). The problem arises due to aspects of both physical and financial accessibilities.

When facing challenges in maintaining food security, resilient households adapt to stresses and shocks (Cooper, 2013; Maxwell, 1996; Mutiah \& Istiqomah, 2017). Maxwell (1996) describes coping strategy as fall back mechanisms to deal with the short-term insufficiency of food. In general, the coping and adaptive strategies chosen tend to reflect the severity of the problem. Maxwell, Caldwell and Langworthy (2008), for example, sets four levels of food insecurity for evaluation: 'not severe', 'quite severe', 'severe' and 'very severe', while Mutiah \& Istiqamoh (2017) use three categories of food insecurity: 'insecure without hunger', insecure with moderate hunger' and 'insecure with severe hunger'. Mutiah and Istiqomah explain that insecurity without hunger, which is the lowest form of food insecurity, is a case where there is little or no reduction in food intake for each house member. On the other hand, the most severe form of food security, i.e. insecure with severe hunger, is a situation when households with children reduce food intake resulting in hunger among the children (Mutiah \& Istiqomah, 2017).

A number of recent studies highlighted how the pandemic is posing a serious threat to food security, specifically on the global food systems, disrupting regional agricultural chains, and posing risks to household food security (e.g. Bhavani \& Gopinath, 2020; FAO, 2020; Hobbs, 2020; Kim, Kim \& Park, 2020). Transportation restrictions during quarantines and lockdowns, shortage of labour (due to limited movement) and closure of restaurants and eateries are among the challenges that affect one's access to food. Other factors such as food prices, food availability and household income are also significant in influencing how a household access food during the pandemic. As stated by the FAO (2020), disruptions and possible breakdowns of marketing, logistics and trading system affect food availability in certain places and those who are affected the most are the vulnerable and the marginalized communities.

There have not been many studies on food security in Sarawak. The limited studies that are available tend to focus on issues such as food security and its tourism potentials (Hashim, Isa, Menon \& Nazari, 2011; Langgat, Zahari, Yasin \& Mansur; 2011), and food safety and nutrition (Cooper, 2013; Rahman, Arif, Bakar \& Talib, 2012). Other issues related to food, such as hunting and foraging activities, are often mentioned briefly in studies on livelihood in Sarawak (e.g. Bennett, 2002; Onn, 2018). Findings from these studies highlighted the different food sources in Sarawak, ranging from the traditional sources (i.e. the forest, river and nature) to the modern and convenient food sources (e.g. supermarkets and groceries stores). 


\section{RESEARCH METHODOLOGY}

The findings and discussion in this paper are based on data that was collected online between May and June 2020. Due to the movement restrictions because of the Covid-19 pandemic, researchers were not able to conduct any fieldwork. Instead, data collection was done online via Google Form. Other scholar, such as Loopstra (2020), has also conducted a study on food security using online platform in the recent months. Loopstra (2020) used the online platform as her research medium in a study about food insecurity during the Covid-19 pandemic in the United Kingdom.

Questionnaire in the form of Google Form was used in this study. The questionnaire was divided into three main sections: (i) securing food before the implementation of the Movement Control Order; (ii) securing food during the Movement Control Order; and (iii) view on their household food security. The unit of analysis in this study is the household, i.e. it can be the head of household or any individual within a household that is familiar with how the household secure their food supply to represent the household to answer the questionnaire. A total of 235 responses were gathered in this study, with approximately $66 \%$ from residents in Kuching Division. This covers the districts of Kuching, Bau and Lundu. The other 34\% are respondents from the rest of Sarawak, ranging from Lawas, Miri, Bintulu, Sibu and Betong.

The limitation of using this method of data collection is that it only targets the respondents who have access to internet network and willing to participate in the study. We acknowledge this limitation but the advantages of using the online method in this study far outweigh its limitations. The method enables us to carry out the study during a period of restricted movement and to gather important data on the issue of food security during the Covid-19 pandemic. The data and the findings are crucial as they set up baseline information on this issue of food security as viewed by the people.

The focus of this paper is on the aspects of food availability and food accessibility, specifically on people's experiences and perception on food security during the Covid-19 pandemic in Sarawak. It does not cover the other two pillars of food security, which are the aspects of utilization and stability. Furthermore, the findings and discussion are place-specific and cannot be generalized to the whole population.

\section{RESULTS AND DISCUSSION}

A total of 235 respondents, from different ethnic groups and areas in Sarawak, participated in the online study. Their profiles are highlighted in Table 1 below. They were asked about their perception on household food security, the challenges of ensuring household food security during the recent $\mathrm{MCO}$ and its subsequent phases, and their patterns of obtaining food before and during the MCO. In the context of this study, respondents from Kuching, Lundu, Bau and Padawan will be categorized as respondents from Kuching Division and the others as from the rest of Sarawak, unless stated otherwise. 
Table 1: Profiles of the respondents, June 2020

\begin{tabular}{lccc}
\hline \hline Categories & & Frequency & Percentage \\
\hline Gender & Male & 118 & 50.2 \\
Ethnicity & Female & 117 & 49.8 \\
& & & \\
& Malay & 71 & 30.6 \\
& Iban & 89 & 38.4 \\
& Bidayuh & 32 & 13.8 \\
& Chinese & 30 & 12.9 \\
& Melanau & 7 & 3.0 \\
& Others & 3 & 1.3 \\
Geographical Location & & 53.2 \\
& Kuching & 125 & 5.5 \\
& Lundu & 13 & 3.8 \\
& Bau & 9 & 3.4 \\
& Padawan & 8 & 34.1 \\
\hline \hline
\end{tabular}

In order to gauge their initial feeling about their food security during the MCO, respondents were asked whether they were worried when the Malaysian Government announced the implementation of MCO. Approximately $63 \%$ of the respondents stated they were worried about their food security when the MCO was announced. In fact, $20 \%$ of them stated that they were very worried, especially regarding the availability and accessibility to food supply for their household. A large proportion (i.e. 69\%) of those who stated that they are worried about their food security are from the other parts of Sarawak, ranging from Lawas, Miri, Bintulu, Sibu, Betong and Sri Aman. Meanwhile, approximately $60 \%$ of those respondents in Kuching indicated that they were worried about securing food during MCO.

Figure 2 below shows the respondents' reaction regarding food security based on ethnic grouping. Respondents in all ethnic groups, except the Chinese, were worried about their food security when the MCO was announced. The most common explanation given by the Chinese respondents about not worrying is that they are located in major cities and town, and, hence, there will not be any shortage of food supply. It should be noted that the respondents who answered in such a way are located in major cities and towns in Sarawak such as Kuching, Miri and Sibu.

Figure 2: Reactions regarding food security, by ethnic group

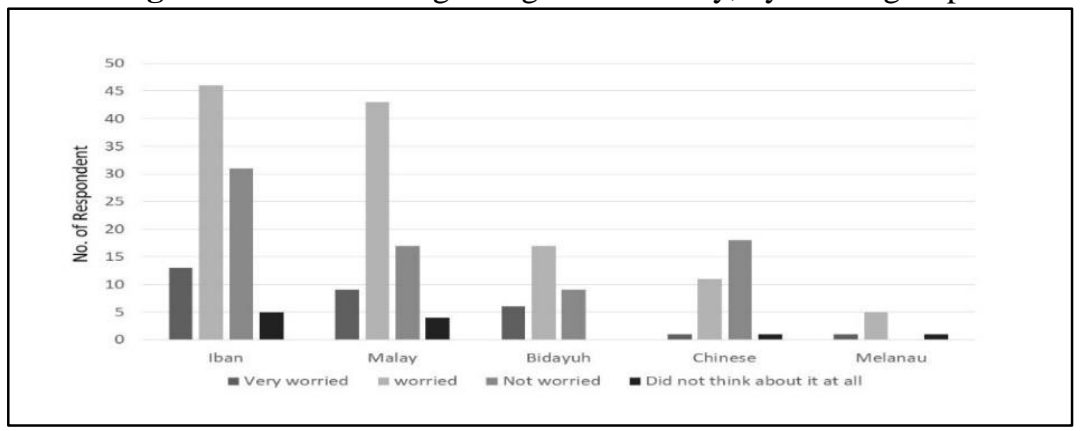


Meanwhile, the Malays, Iban and Bidayuh who live in urban areas expressed their worry, especially in relation to the availability and accessibility of food. The Iban and the Malays in Kuching, for instance, were worried about whether they can access the same amount and the same variety of food that they normally have prior to the implementation of the MCO. In this context, they were concerned about the availability of their favorite jungle produce and/or fish as these items are usually available in wet markets and produce markets. Local vegetables such as midin, bamboo shoots, and pucuk paku were among the food items listed.

Other than that, respondents were also asked about their purchasing behavior in time prior to the Covid-19 pandemic as well as during the Covid-19 pandemic. Three main sources of food identified are the wet market (for fresh meat, fish and vegetable produce), the grocery stores and the supermarkets. This is shown in Figure 3 below. In this paper, grocery stores refer to small sundry shops and/or convenience stores, selling household items including food and other essential items. They are usually family-run businesses and often found in residential areas. Meanwhile, supermarket refers to larger stores, selling household goods and food items, usually at a larger scale than the grocery stores.

Figure 3: Sources of food supply before and during the MCO period

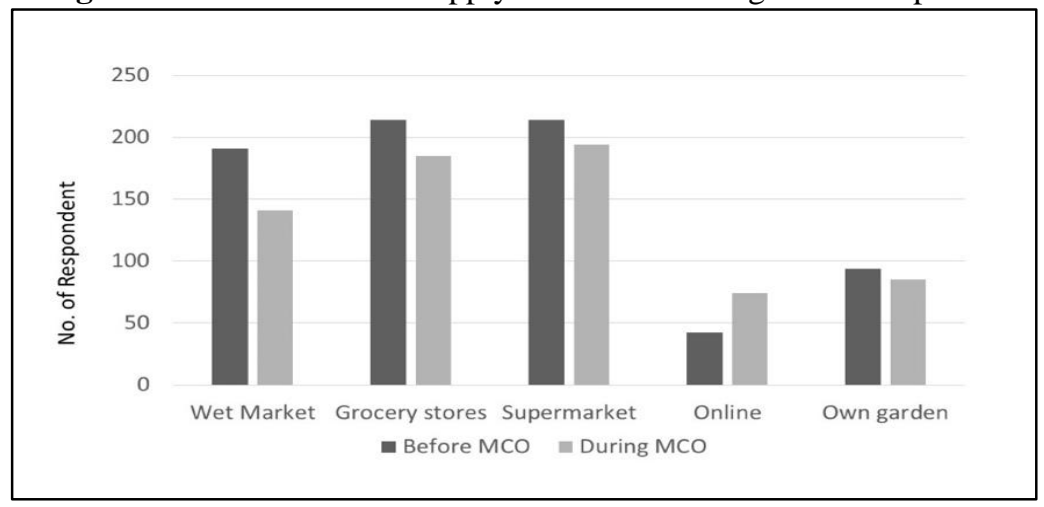

As shown in Figure 3 above, the proportion of people getting their food supply from all sources, except online shopping, has declined during the MCO period. This fall is attributed mainly to the movement restriction that was imposed in the country. During the period, people were urged to only travel within $10 \mathrm{~km}$ of their residences and only for essential trips. The latter includes shopping for food and other essential items. This restriction in term of distance travelled had influenced the shopping behavior of the respondents. In the words of a respondent (43 years old male) who is based in Kuching,

"I have to switch to the supermarket nearer to home because I was not able to travel to our usual supermarket [located in one of the shopping malls in Kuching] because it is more than $10 \mathrm{~km}$ away ..."

Another respondent, from the outskirt of Kuching states that, 
“... during the MCO, I cannot travel far to our usual market place ... I have to make do with what is available at the nearby grocery store ... which, in normal days, we very rarely visit ..."

Similarly, respondents outside of Kuching Division also faced the same dilemma. A majority of them stated that, because of the restricted movement, they cannot access the fruits and vegetables from their farms or other non-market places during the MCO period. That explains why the proportion of people relying on their home garden as a source of food actually declined during the MCO period. An elderly respondent from Betong, for example, mentions that his family members were not able to forage the forest for fresh jungle produce and, hence, having to rely on vegetables from the supermarket and grocery stores. He further reiterates that such change is costly as they need cash to buy the fruits and vegetables they needed from the stores and/or supermarket. This links to the concept of food accessibility (e.g. financial access and physical access to food) and food availability (variety, quantity, and choices) that were discussed earlier.

The study also found that approximately $31.5 \%$ of the respondents have indicated that they prefer to do online shopping for their food supply during the Covid-19 pandemic and the MCO period. This is a slight increase from $17.8 \%$ prior to the MCO. Of those who opted for online shopping during the MCO, roughly $36.8 \%$ are respondents from Kuching and $21.3 \%$ from the rest of Sarawak. It is also observed that respondents who are located in semi-urban or rural locations (e.g. Bau and Lundu in Kuching Division) had mentioned that they do not have the luxury of online shopping option. They argued that their area has no access to online sellers and/or has poor choices of online sellers and the type of items that they sell. In other words, they have no choice but to rely on other methods of accessing food during the MCO.

Citing safety issues and the need to distance themselves from crowded markets and/or supermarkets, several respondents argued that they feel safer when purchasing food items online. This group of respondents resorted to buying fruits and vegetables, fish and crustaceans, cakes, desserts and other food items from online sellers, supermarket that does home-delivery and other form of delivery services. One respondent, a 68 year old woman from Kuching, said that,

“... I am old and was told to stay at home during the Covid-19 pandemic ...I cannot go to the market to get fish and prawns that we normally have every week ...didn't have it for two months until my daughter managed to get fresh seafood delivered to our doorstep ...she bought them from Facebook [online seller] ..."

The respondent further reiterates that she would not normally do online shopping as she prefers to go to the market and choose the food items herself to ensure their freshness and quality. This view was shared by a number of other respondents, in all locations, particularly those aged 55 years old and above. They cited the need to actually choose their own food item, checking for quality and also comparing prices as reasons for this preference. The Covid-19 pandemic and the MCO, to a large extent, had affect their physical access to market (and hence, access to their preferred food).

Aside from that, a large proportion of those who opted for online shopping during the MCO period stated that they have to spend more on food items compared to before the MCO started. Buying online, according to them, is more expensive as it may incur additional fees such as delivery charges, and the imposition of minimum purchase limit. A large proportion of the respondents 
(equivalent to 64\%) who shopped online for food believed that the prices are higher than if they were to go to the supermarket yourself. This adds to their overall household food expenses and, to some extent, a strain to their household food budget and financial standing.

Having said that, almost all of those who have opted for online shopping during the MCO period agreed that shopping online has increased their access to food despite the movement restriction. Approximately $80 \%$ of them stated that they have good access to food via online platform. Online shopping has enabled the respondents to obtain items that are not available near them. The nature of online shopping means their access to, and choices of, food is expanded. The access is further facilitated by the existence of delivery services (e.g. Food Panda, Grab Food and local 'runners' that collaborate with the online sellers).

One of the shortcomings of online shopping for food items, according to the respondents, is the limited choices or variety of items that are available. This seems to contradict the earlier discussion but in actual fact it is contextually different. A number of respondents who engaged in food online shopping stated that they do not know the quality of food that they ordered. This, according to the respondents, refers to the freshness as well as the quantity of the item (e.g. portion sizes). Approximately $37 \%$ of those who shopped online state that the choices available are limited and $32 \%$ said that most of the items they wanted were not available when they needed them. The former is about choices and varieties of food items and the latter is more on stock availability. Having said that, approximately $22 \%$ believed that they have plenty of choices while shopping online and $50 \%$ stated that the stock of food items that they want is always available. It should be noted that the view is subjective as it highly depends on people's food preferences.

Overall, approximately $93 \%$ of the respondents stated that their households are food secure during the Covid-19 pandemic and the MCO period. In this context, almost all of the respondents said that as they were able to obtain the same amount of food as before the MCO started, able to have three meals a day and always have food in the house. This, to a certain extent, also attests to the resilience of the household in overcoming food insecurity. As Ansah et al., (2019) point out, households with higher resilience capacity to deal with challenges of food security are more likely to have better and more stable food security system than households with lower resilience capacity.

The other $7 \%$ (i.e. 17 out of 235 respondents) stated that they face food insecurity during the MCO period, namely because they cannot afford to get the same amount of food for the family. One respondent stated that,

"My husband is on daily pay and he cannot work during the MCO period ... our income has decreased a lot during this period ...we only buy essential food stuffs and try to save the rest of the income ... we still eat three meals a day but not like before ..."

Out of 17 respondents who stated that they face food insecurity, 11 are from Kuching and the other six are from the rest of Sarawak. Out of the 17, seven respondents reported that they are highly insecure in terms of food security during the MCO period. Their food security is compromised, specifically in terms of the types and variety of food that they consumed, their level of access to food is affected by financial constraints and inability to get the same amount of food that they normally have. In particular, these aspects are all related to their financial insecurity. According to Mutiah and Istiqomah's (2017) categories of food security, these households can be classified as 
its Level 1 severity: 'insecure without hunger'. This category implies that there is little or no reduction in food intake for each household member. However, it is also important to take note that, if situation persists, the household may fall into category 2 of the severity level (i.e. insecure with moderate hunger).

On the other hand, there are respondents who argued that, despite having sufficient food for the household and not having to skips any meals, they actually missed their preferred food, favourite cafes and takeaways, and specific brands of goods that they love which were not available or accessible to them during the MCO period. In fact, they argued that, during the MCO period, although the supermarkets are stocked up pretty well, they were not able to get certain brands that they normally buy or that there were not much choices available in the shopping aisles. A third of the respondents also highlighted the fact that they had to resort to shop at other places (e.g. at a grocery store instead of a supermarket) near to their residences at that time, thus limiting their choices of food. This highlights the fact that food security means more than just having enough food for each household member. Food security, as defined by the FAO (1996), is multidimensional in nature.

In general, the respondents were quite optimistic when asked about the future challenges that they may face with regards to ensuring their household food security. Two third of the respondents stated that they and their families would have to adapt to the 'new norms' especially when dealing with daily routines post Covid-19. Approximately $82 \%$ of the respondents stated that they would be revisiting how their household obtain the food items post-MCO. A large proportion stated that they will avoid food wastage and only be buying just enough for their household. Additionally, about half of the respondents indicated that they have decided to start their own vegetable gardens at their backyards. This measure, according to them, would enable them to get continuous supply of vegetables as well as safe and fresh food. This garden-to-table concept, as well as reducing food waste, are very much in line with the target of the SDGs. As one respondent said,

"After experiencing life during the Covid-19 pandemic and the challenges during the MCO, having your own vegetable garden will be a blessing ... able to get fresh, safe and unlimited supply of food for the family ... to be self-sufficient will be great for the family..."

Other than that, there are respondents who felt that buying food via online medium would be more attractive in the post Covid-19 period. They argued that having the options of buying online and buying at the market places would give them the freedom to choose. This goes back to the concepts of food availability and accessibility. As one respondent succinctly puts it 'do we really have to go back to our usual way of shopping when we (now) know online shopping is also convenient, accessible and practical?'

\section{CONCLUSION}

As highlighted in the discussion above, a great majority of the respondents in this study indicated that they are food secure during the Covid-19 pandemic and the MCO period. Despite the restrictions imposed by the Government of Malaysia, the respondents still managed to cope and find alternative ways to ensure that their household are food secure. Measures such as finding 
alternative food sources, trying out different market places, and opting for online food shopping have been cited as their short-term coping strategies during the MCO period.

However, as the study highlights, food security is not just about being able to obtain enough food and/or able to afford the food (financial accessibility) or to get the food at the market places (physical accessibility). There are more to food security than that simplistic explanation of availability and accessibility. People often equates food security with having enough food for everyone. As long as a household is not skipping any meals or reducing their food sizes, it is assumed that the households are food secured. Alas, that may be a little inaccurate. The findings of this study have indicated that while food availability is crucial, other elements such as variety, choices and quantity of food that are available are also important. So, in this context, it means that the notion of food availability should include the elements of quantity, choices as well as the types of food that are available.

The study also found that a small proportion of the respondents have indicated that they faced food insecurity during the MCO period. This shift from security to insecurity occurred because of the financial constraints resulting from the Covid-19 and MCO related closure of the economy. This is particularly worrying, especially if the pandemic continues to impact the economy and many more households could fall under this food insecurity trap. The greatest challenge in achieving and maintaining household food security lies in the way household cope with the changes brought, both directly and indirectly, by the pandemic. As discussed earlier, factors such as availability, accessibility, affordability, and choices are influential in determining whether the household is food secure or otherwise. The way forward would be to think of how we as individuals, and a member of a community, could do to ensure household food security. Adapting to the new norms, such as producing own food, starting a home garden at the backyards, or resorting to online food shopping, is an option to expand food accessibility and availability. However, there might be other options that are available out there and yet to be explored.

The data and findings of this study are significant as they could provide an overview of people's perception and experiences on food security during the MCO period as well as during the Covid19 pandemic in Sarawak. As Galanakis (2020) points out, the Covid-19 pandemic crisis has created a new era and we are still trying to figure out the consequences for humanity, economy, and subsequently, the food system. Thus, the findings of this study could be further expanded in the future in order to address more questions on food security that arise from the Covid-19 pandemic as well as the issues that crop up because of the implementation of the MCO and its subsequent phases.

\section{ACKNOWLEDGEMENT}

The authors wish to thank the Ministry of Higher Education for funding this project (RACER/1/2019/SS06/UNIMAS//1), Universiti Malaysia Sarawak for its constant support and encouragement, and, last but not least, a heartfelt gratitude to all the respondents for their participation and co-operation. 


\section{REFERENCES}

Ansah, I. G. K., Gardebroek, C., \& Ihle, R. (2019). Resilience and household food security: A review of concepts, methodological approaches and empirical evidence. Food Security, 11, 1187-1203.

Bennett, E. L. (2002). Is there a link between wild meat and food security? Conservation Biology, 16(3), 590-592.

Bhavani, R. V., \& Gopinath, R. (2020). The COVID19 pandemic crisis and the relevance of a farm-system-for-nutrition approach. Food Security, 12, 814-884. doi: 10.1007/s12571020-01071-6

Bublitz, M. G., Czarkowski, N., Hansen, J., Peracchio, L. A., \& Tussler, S. (2020). Pandemic Reveals Vulnerabilities in Food Access: Confronting Hunger Amidst a Crisis. Journal of Public Policy \& Marketing, 1-3. doi: 10.1177/0743915620929998

Capone, R., Bilali, H. E., Debs, P., Cardone, G., \& Driouech, N. (2014). Food system sustainability and food security: connecting the dots. Journal of Food Security, 2(1), 13-22.

Cooper, E. E. (2013). Evaluating household food insecurity: applications and insights from rural Malaysia. Ecology of food and nutrition, 52(4), 294-316.

Food and Agriculture Organization (FAO) (1983). Committee on World food security (CFS 83/4): Director Generals Report on Food Security: A reappraisal of the concepts and approaches. Rome. Retrieved from https://agris.fao.org/agris-search/search. do?recordID=XF8333115

Food and Agriculture Organization (FAO) (1996). Rome Declaration on World Food Security and World Food Summit Plan of Action: World Food Summit 13-17 November 1996, Rome, Italy. Retrieved from http://www.fao.org/3/w3613e/w3613e00.htm

Food and Agriculture Organization (FAO) (2006). Food security. Policy Brief, 2, 1-4. Retrieved from http://www.fao.org/fileadmin/templates/faoitaly/documents/pdf/pdf_Food_ Security_Cocept_Note.pdf

Food and Agriculture Organisation (2020). Impacts of coronavirus on food security and nutrition in Asia and the Pacific: Building more resilient food systems. Retrieved from http://www.fao.org/3/ca9473en/CA9473EN.pdf

Galanakis, C. M. (2020). The Food Systems in the Era of the Coronavirus (COVID-19) Pandemic Crisis. Foods, 9(4), 523.

Hashim, M. S., Isa, A. M., Menon, A. S., \& Nazari, N. M. (2019). The Effect of Tourism Towards the Food Security Issues to the Urban Poor in Sarawak, Malaysia: A Conceptual Approach. International Journal of Financial Research, 10(5), 241-249.

Hobbs, J. E. (2020). Food supply chains during the COVID-19 pandemic. Canadian Journal of Agricultural Economics, 2020(S), 1-6. doi: https://doi.org/10.1111/cjag.12237

Kim, K., Kim, S., \& Park, C. Y. (2020). Food Security in Asia and the Pacific amid the COVID19 Pandemic. ADB Brief No. 139. Manila, Philippines: Asian Development Bank. Retrieved from https://www.adb.org/sites/default/files/publication/611671/adb-brief139-food-security-asia-pacific-covid-19.pdf

Langgat, J., Zahari, M. S. M., Yasin, M. S., \& Mansur, N. A. (2011, March 14-16). The alteration of Sarawak ethnic natives' food: it's impact to Sarawak state tourism. In 2nd International Conference on Business and Economic Research Proceeding, 684-698. Langkawi, Kedah, Malaysia. 
Loopstra, R. (2020). Vulnerability to food insecurity since the COVID-19 lockdown. The Food Foundation. Retrieved from https://foodfoundation.org.uk/wpcontent/uploads/2020/04/Report_COVID19FoodInsecurity-final.pdf

Mat Akhir, A., Omar, R., \& Abd Hamid, H. (2009, November 11-13). Food security-A national responsibility of regional concern: Malaysia's case. Paper presented at the Conference on Food Security and Sustainable Development (pp. 11-13), Rome. Retrieved from http://www.idra.it/garnetpapers/C01A_M_Akhir_RoziahOmar_HamidinAbdHamid.pdf

Maxwell, D. G. (1996). Measuring food insecurity: the frequency and severity of "coping strategies". Food Policy, 21(3), 291-303. doi:10.1016/0306-9192(96)00005-x

Maxwell, D., Caldwell, R., \& Langworthy, M. (2008). Measuring food security: Can an indicator based on localized coping behaviours be used to compare across contexts? Food Policy, 33, 533-540.

Maxwell, S., \& Smith, M. (1992). Household food security: a conceptual review. Household food security: Concepts, indicators, measurements. New York: UNICEF Programme Publications.

Mutiah, S., \& Istiqomah, I. (2017). Determinants of Household Food Security in Urban Areas. JEJAK: Jurnal Ekonomi Dan Kebijakan, 10(1), 103-120. doi: 10.15294/jejak.v10i1.9130

Onn, L. P. (2018). Property rights, food security, and gender: The impact of the expansion of palm oil plantations on native communities in Sarawak, Malaysia. In Devasahayam, T. W (Eds.), Ensuring a square meal: Women and food security in Southeast Asia, (pp. 147169).

Rahman, M. M., Arif, M. T., Bakar, K., \& Talib, Z. (2012). Food safety knowledge, attitude and hygiene practices among the street food vendors in Northern Kuching City, Sarawak. Borneo Science, 31, 107-116.

Rosegrant, M. W., \& Cline, S. A. (2003). Global food security: challenges and policies. Science, 302(5652), 1917-1919.

Sharif, Z. M., \& Ang, M. (2001). Assessment of food insecurity among low income households in Kuala Lumpur using the Radimer/Cornell food insecurity instrument-a validation study. Malaysian Journal of Nutrition, 7(1), 15-32.

World Health Organisation (WHO) (2020). Director-General's Opening Remarks at the Media Briefing on COVID-19-11 March 2020. Retrieved from https://www.who.int/dg/speeches/detail/who-director-general-s-opening-remarks-at-themedia-briefing-on-covid-19---11-march-2020 